\title{
Semi-Solid and Solid Bolus Swallows in High-Resolution Oesophageal Manometry for the Detection of Motility Disorders
}

\author{
Jerry Zhou ${ }^{*}$, Catherine Sykes ${ }^{2}$, Vincent Ho ${ }^{1,3}$ \\ ${ }^{1}$ School of Medicine, Western Sydney University, Sydney, Australia \\ ${ }^{2}$ Gastrointestinal Physiology and Urodynamics, Royal Infirmary of Edinburgh, Edinburgh, Scotland \\ ${ }^{3}$ Gastroenterology, Campbelltown Hospitals, Campbelltown, Australia \\ Email: jwerner_juarez@hotmail.com
}

How to cite this paper: Zhou, J., Sykes, C. and Ho, V. (2018) Semi-Solid and Solid Bolus Swallows in High-Resolution Oesophageal Manometry for the Detection of Motility Disorders. Open Journal of Gastroenterology, 8, 1-16.

https://doi.org/10.4236/ojgas.2018.81001

Received: December 15, 2017

Accepted: January 22, 2018

Published: January 25, 2018

Copyright (c) 2018 by authors and Scientific Research Publishing Inc. This work is licensed under the Creative Commons Attribution International License (CC BY 4.0).

http://creativecommons.org/licenses/by/4.0/

\begin{abstract}
Background/Aims: High-resolution oesophageal manometry utilises water swallows to evaluate oesophageal function. However, small volumes of water are not representative of normal eating and as a result often produce normal manometry studies in patients with dysphagia. This study sets out to establish optimal diagnostic thresholds for semi-solid solid swallows and evaluate their ability to uncover motility abnormalities in patients with motility disorders. Method: Manometry was performed using ten $5-\mathrm{mL}$ single water swallows followed by two semi-solid and two solid swallows in the upright position. Normative values for the adjunctive tests were obtained from patient controls while patients with major motility disorders were used to establish the optimal diagnostic thresholds. Diagnostic thresholds identified were prospectively tested in patients with normal water swallows but oesophagus related symptoms and in those with minor and major motility disorders. Results: Normal values for semi-solid and solid were determined in patient controls $(n=100)$. Development of diagnostic thresholds included 120 patients with major motility disorders. Optimal diagnostic thresholds identified for oesophagogastric junction dysfunction in semi-solid and solid swallows (IRP > $15.5 \mathrm{mmHg}$ ). Hypercontractilty and spasm used existing thresholds $(>8000 \mathrm{mmHg}-\mathrm{s}-\mathrm{cm}$ and $<$ $4.5 \mathrm{~s}$, respectively) but modified frequency of $\geq 50 \%$ of adjunctive swallows. Diagnostic thresholds were applied to symptomatic patients with normal water swallows $(\mathrm{n}=70)$ identifying $12 / 70(17 \%)$ to have abnormal adjunctive swallows. One of 30 patients (3\%) with ineffective motility had abnormal adjunctive swallow and 12 patients with oesophageal spasm, oesophagogastric junction obstruction, and hypercontractility had abnormal adjunctive swallows that moved them up the motility disorder hierarchy. Conclusions:
\end{abstract}


Semi-solid and solid challenge increase diagnostic yield of motility disorders.

\section{Keywords}

High-Resolution Manometry, Oesophagus, Motility, Diagnostic Classification, Bolus Type

\section{Introduction}

The development of high-resolution oesophageal manometry (HRM) has rapidly revolutionised the investigation of oesophageal motility disorders and has become the gold-standard of diagnosis. The HRM catheter consists of 36 solidstate pressure sensors and provides a topographical pressure map describing oesophageal contractility from the pharynx to the stomach. Despite its impressive capabilities, HRM can only detect pathophysiology that is present during the study. Therefore, the most challenging aspect of identifying oesophageal disorders is providing a diagnosis that is representative of all the pathologic oesophageal motor abnormalities experienced by the patient.

Standard operating procedure for HRM testing involves the patient seated in an supine position and performing ten 5-mL single water swallows (SWS) based on criteria described in Chicago Classification version 3.0 (CCv3.0) [1]. This approach is limited as water swallows provide only indirect evidence about the cause of symptoms when eating solids and sometimes symptoms are not triggered at all by water swallows alone [1]. This suggests that water swallows may not always be the optimum bolus type for patients with dysphagia to swallow during HRM. Although many physicians are fully aware of these limitations, the lack of standardisation for different types of swallowing tests prevents them from being used routinely in standard clinical practice.

The addition of semi-solid and solid swallows to HRM has been shown to increase sensitivity for clinically relevant dysmotility [2]. Normative HRM data for a variety of adjunctive tests have been reported in several studies involving swallow tests with semi-solids [3], solids [4], or a mixture of both [5]. The inclusion of adjunctive swallows more representative of normal eating behaviour attempts to trigger symptoms by "challenging" oesophageal function during HRM. However, unlike their water counterpart, semi-solid and solids bolus tests can be more difficult to interpret as they are not always transported through the oesophagus with a simple peristaltic contraction [2]. Complex pressure activity can occur, posing challenges for analysis which can impair inter-investigator agreement, decreasing specificity of clinical diagnosis [1]. Studies with different bolus types, apple sauce [3], marshmallow [2], pasty with smoothie [5], have all found the inclusion of novel non-liquid bolus swallows to increase diagnostic yield in patients with dysphagia. However, to date, there has not been a comprehensive evaluation of semi-solid and solid swallows in patients with major motility disorders to establish and evaluate diagnostic thresholds. This study aims to: 
1) Establish normal values and diagnostics thresholds for semi-solid and solid swallows;

2) Evaluate the ability of semi-solid and solid swallows to increase diagnostic yield by the identification of classifiable motility disorders unnoticed in water swallow.

\section{Methods and Material}

\subsection{High-Resolution Oesophageal Manometry}

Patients with oesophagus related symptoms or reflux symptoms are referred to the Gastroenterology (GI) Motility Clinic, Camden Hospital (Sydney, NSW, Australia) for HRM (ManoSan ESO high resolution manometry system; Medtronic, Minneapolis, Minnesota, USA) assessment of oesophageal motility and function based on standard 5-mL SWS in accordance with the CCv3.0 [1], modified for use in the upright position [4]. Patients with reflux symptoms also undergo $24 \mathrm{hr}$ ambulatory $\mathrm{pH}$ monitoring with Digitrapper system (Medtronic, Minneapolis, Minnesota, USA) [6]. Patients attending HRM studies as part of routine care were recruited between 2014 and 2017. "Patient controls" were individuals referred for investigation of reflux-associated symptom but with a normal HRM study based on CCv3.0 and normal 24-hour pH studies. Patients with dysphagia symptoms but normal SWS and 24-hour $\mathrm{pH}$ studies were not included in our "patient controls" and were analysisd as a separate group of normal HRM patients with dysphagia symptoms. Patients diagnosed with minor motility disorder (ineffective motility) and major motility disorders (oesophageal spasm, hypercontractiliy/jackhammer, oesophagogastric junction obstruction, and Type I-III achalasia) by CCv3.0 were categorised into their respective groups for analysis. Adjunctive tests conducted included two semi-solid bolus swallows with a tea spoon $(3.5 \mathrm{~mL})$ of custard $\left(1.07 \mathrm{~g} \cdot \mathrm{cm}^{-3}\right)$ or jelly $\left(1.24 \mathrm{~g} \cdot \mathrm{cm}^{-3}\right)$ as a lactose-free alternative, and two solid bolus swallows with a single unmasticated $1.2 \mathrm{~cm}^{3}$ marshmallow $\left(0.37 \mathrm{~g} \cdot \mathrm{cm}^{-3}\right)$. For semi-solid and solid swallows, patients with motility disorders often needed to swallow more than once to clear the pharynex. The number of pharyngeal deglutinations prior to effective distal oesophageal contraction was recorded as "attempts". Following pharyngeal deglutination(s), a swallow was considered simultaneous if the distal oesophageal contraction had a contraction front velocity of $>5.3 \mathrm{~cm} \cdot \mathrm{s}^{-1}$ and as failed if no distal oesophageal contraction occurred [4]. Participants abstained from acid suppression and prokinetic medications 3 days prior to the study and a minimum 4-hour fast. Demographic data, symptoms, endoscopy findings, current medication, past medical and surgical history were recorded. Informed consent was obtained from all patients. All patients and controls provided permission for data to be analysed. Studies were approved by South West Sydney Local Health District ethics committees (Ref: LNR/17/LPOOL/244). Proprietary software analysis HRM spatiotemporal plots (ManoView ESO v3.0.1; Medtronic, Minneapolis, Minnesota, USA) with measurements referenced to gastric pressure. 
Acid reflux was analysed and diagnosis with AccuView v3.0 Reflux Software (Medtronic, Minneapolis, Minnesota, USA).

Power calculation (Type I error rate 0.05 ; power $90 \%$ ) using manometry perimeters from literature determined a minimum of 25 studies per group are required for adequate study power [2] [3]. We used 100 control studies and 120 abnormal studies (30 per disorder group) to establish thresholds.

\subsection{Statistical Analysis}

Optimal diagnostic thresholds for integrated relaxation pressure (IRP) during adjunctive tests were identified by "receiver operating characteristic" (ROC) analysis. Patient controls and patients with major motility disorders were used to establish diagnostic thresholds. Diagnosis based on CCv3.0 was the reference standard. Following the approach used by the Chicago Classification [7], diagnostic thresholds for IRP semi-solid and solid tests were refined using results in results from cases of EGJ dysfunction (achalasia and EGJ outlet obstruction) to define clinically relevant, abnormal EGJ function. CCv3.0 thresholds for hypercontractility (jackhammer) and oesophageal spasm, distal contractile integral (DCI $>8000 \mathrm{mmhg} \cdot \mathrm{cm} \cdot \mathrm{s})$ and distal latency (DL $<4.5 \mathrm{~s})$ were used for adjunctive swallows with modified swallow frequencies (abnormality noted in $\geq 50 \%$ of adjunctive swallows).

Patient data are reported as either median $(95 \% \mathrm{CI})$ or mean \pm SD where appropriate. The statistical analysis first established normative values for adjunctive tests, reported as median (99\% confidence intervals [CI]). Optimal diagnostic thresholds based on ROC findings were identified in the data set. An area under the ROC curve (AUC) 0.80 - 0.90 defined "good" and $>0.90$ "excellent" accuracy for medical tests [8]. Sensitivity and specificity, positive and negative predictive values, likelihood ratios, and numbers need to diagnosis (NND) for these thresholds were prospectively assessed in patients with major, minor and normal HRM patients with oesophagus-associated symptoms. The established diagnostic thresholds were used to analysis patients with minor motility disorders and patients with oesophagus-related symptoms but classified as normal by CCv3.0. Inter-group differences were compared using Student's t-test (unpaired, two tailed) for quantitative variables. Pairwise differences were analysed with Wilcoxon signed rank test. Statistical analysis was performed using the statistical software SPSS 24.0 package (SPSS Inc., Chicago, Illinois, USA) for Windows.

\section{Results}

\subsection{Participants}

Demographic and clinical data for study groups are presented in Table 1. Patient controls comprised of 100 patients referred for reflux-related symptoms with normal HRM and $24 \mathrm{hr}$ pH-studies (40 [40\%] male; mean age $50 \pm 15$ years). The development of the diagnostic threshold used 120 patients with major motility disorders (42 [35\%] male; mean age $59 \pm 15$ ). The comparison 
Table 1. Demographic data for controls and disorder groups $(n=320)$.

\begin{tabular}{|c|c|c|c|c|c|}
\hline $\begin{array}{l}\text { Oesophageal } \\
\text { motility }\end{array}$ & Category & Subjects (N) & $\begin{array}{c}\text { Age } \\
(\text { mean } \pm S D)\end{array}$ & Male: Female & Symptom \\
\hline \multirow{4}{*}{ Normal } & \multirow{4}{*}{ Patient controls } & \multirow{4}{*}{100} & \multirow{4}{*}{$50 \pm 15$} & \multirow{3}{*}{$40: 60$} & Dyspepsia 71 \\
\hline & & & & & Heartburn 11 \\
\hline & & & & & Cough 9 \\
\hline & & & & \multirow{5}{*}{ 28:42 } & Hoarseness/sore throat 9 \\
\hline \multirow{4}{*}{ Normal } & \multirow{4}{*}{ Dysphagia symptoms } & \multirow{4}{*}{70} & \multirow{4}{*}{$50 \pm 17$} & & Difficulty swallowing35 \\
\hline & & & & & Difficulty swallowing solids 10 \\
\hline & & & & & Choking/food stuck 8 \\
\hline & & & & & Pain while swallowing 17 \\
\hline \multirow{3}{*}{ Minor disorder } & \multirow{3}{*}{ Ineffective motility } & \multirow{3}{*}{30} & \multirow{3}{*}{$51 \pm 14$} & \multirow{3}{*}{ 20:10 } & Heartburn 5 \\
\hline & & & & & Dyspepsia 17 \\
\hline & & & & & Difficulty swallowing 8 \\
\hline \multirow{14}{*}{ Major disorder } & \multirow{2}{*}{ Type I achalasia } & \multirow{2}{*}{20} & \multirow{2}{*}{$57 \pm 17$} & \multirow{2}{*}{ 9:11 } & Unable to swallow 18 \\
\hline & & & & & Reflux 2 \\
\hline & \multirow{2}{*}{ Type II achalasia } & \multirow{2}{*}{20} & \multirow{2}{*}{$51 \pm 21$} & \multirow{2}{*}{ 9:11 } & Difficulty swallowing 13 \\
\hline & & & & & Pain while swallowing 7 \\
\hline & \multirow{2}{*}{ Type III achalasia } & \multirow{2}{*}{20} & \multirow{2}{*}{$65 \pm 12$} & \multirow{2}{*}{$8: 12$} & Difficulty swallowing 7 \\
\hline & & & & & Pain while swallowing 13 \\
\hline & \multirow{3}{*}{$\begin{array}{l}\text { EGJ outflow } \\
\text { obstruction }\end{array}$} & \multirow{3}{*}{20} & \multirow{3}{*}{$61 \pm 11$} & \multirow{3}{*}{ 3:17 } & Difficulty swallowing 6 \\
\hline & & & & & Dysphagia 13 \\
\hline & & & & & Aspiration 1 \\
\hline & \multirow{3}{*}{ Jackhammer } & & & & Difficulty swallowing 11 \\
\hline & & 20 & $55 \pm 14$ & 6:14 & Pain while swallowing 7 \\
\hline & & & & & Dispepsia2 \\
\hline & Oeconbagenl $\mathrm{cmasm}$ & 20 & $53+18$ & $7 \cdot 13$ & Difficulty swallowing 15 \\
\hline & & & 的 10 & 1.10 & Pain while swallowing 5 \\
\hline
\end{tabular}

EGJ, oesophagogastric junction.

groups consisted of 70 patients with dysphagia symptoms but classified normal by CCv3.0 (28 [40\%] male; mean age $50 \pm 17$ years), 30 patients with minor motility disorders (20 [67\%] male; mean age $51 \pm 14$ years).

\subsection{Semi-Solid and Solid Swallows in Patient Controls}

HRM metrics for patient controls are presented in Table 2. The SWS HRM metrics, using $99 \% \mathrm{Cl}$, for all patients controls $(\mathrm{n}=100)$ were within the standard normal ranges set by CCv3.0 [1]. There were no significant differences in the swallowing parameters between the two types of semi-solids $(3.5 \mathrm{~mL}$ of custard $\mathrm{n}=57$ and jelly $\mathrm{n}=43$ ) and, therefore, these data were combined for the semisolid analysis. The semi-solid and solid swallows had elevated IRP compared to SWS (7.8 vs $5.2 \mathrm{mmHg} \mathrm{p}<0.001 ; 7.2$ vs $5.2 \mathrm{mmHg} \mathrm{p}<0.01$ ). Using $99 \% \mathrm{Cl}$, the upper limits of the adjunctive tests were above normal limits for SWS but in these patients the LES does appear to relax despite raised IRP. The UES relaxation 
Table 2. Normative values for adjunctive tests in patient controls $(\mathrm{n}=100)$.

\begin{tabular}{|c|c|c|c|c|c|c|}
\hline \multicolumn{7}{|c|}{ Median $\left(5^{\text {th }}\right.$ and $99^{\text {th }}$ percentile $)$} \\
\hline Swallow type & $\begin{array}{c}\text { Integrated } \\
\text { relaxation pressure } \\
(\mathrm{mmHg})\end{array}$ & $\begin{array}{l}\text { Distal contractile } \\
\text { integral } \\
\left(\mathrm{mmHg} \cdot \mathrm{cm}^{-1} \cdot \mathrm{s}^{-1}\right)\end{array}$ & Distal latency (s) & $\begin{array}{l}\text { Upper oesophageal } \\
\text { sphincter relaxation } \\
\text { pressure }(\mathrm{mmHg})\end{array}$ & Attempts $^{\mathrm{a}}$ & $\begin{array}{l}\text { All swallows failed } \\
\text { (patients/100 [\%]) }\end{array}$ \\
\hline Single water & $5.1(0.2-14.8)$ & $1481(621-3879)$ & $6.5(5.1-9.4)$ & $0.9(-6.4-12.0)$ & N/A & $0(0)$ \\
\hline Semi-solid & $6.9(1.2-20.8)^{\star \star *}$ & $1132(231-5198)$ & $7.1(4.8-10.1)$ & $-0.9(-10.8-15.1)^{\star *}$ & $2(1-4)$ & $4(4)$ \\
\hline Solid & $6.5(1.0-19.7)^{\star *}$ & $1150(286-4729)$ & $6.5(4.3-9.6)$ & $-1.7(-12.0-13.7)^{\star * *}$ & $3(1-5)$ & $2(2)$ \\
\hline
\end{tabular}

${ }^{a}$ Attempts indicates the number of pharyngeal deglutinations before peristaltic contraction was observed; $\mathrm{p}$-value $<0.05^{\star}<0.01^{\star *}<0.001^{\star * *}$ compared to $5-\mathrm{mL}$ single water swallow values.

pressure was much lower in semi-solid and solid swallows than SWS ( -0.7 vs 1.3 $\mathrm{mmHg} \mathrm{p}<0.01 ;-1.6$ vs $1.3 \mathrm{mmHg} \mathrm{p}<0.001)$. Patient controls completed the semi-solid swallow in fewer attempts (pharyngeal deglutitions) than the solid swallow (median semi-solid swallow 2 attempts vs solid swallow 3 attempts).

\subsection{Semi-Solid and Solid Swallows in Patients with Major Motility Disorders}

Comparison of SWS and adjunctive test metrics in patients with major motility disorders are presented in Table 3. IRP in semi-solid and solid swallows were higher than SWS-IRP in all major motility disorders, except achalasia. Only Type II achalasia had higher IRP for solid swallows than SWS. In contrast, UES relaxation pressures were lower in adjunctive tests than SWS in all major disorders, except achalasia. Oesophagus shortening was noted during adjunctive tests in Type II and III achalasia patients (semi-solid 2/40 [5\%]; solid 3/40 [7.5\%]). Oesophageal pressurisation was noted more frequently in EGJ outflow obstruction patients with semi-solid $(8 / 20[40 \%])$ and solid swallows $(12 / 20[60 \%])$ than in liquid $(6 / 20[30 \%])$. Two EGJ outflow obstruction (2/20 [10\%]) studies had premature contractions and spastic features not evident in the SWS while pan-oesophageal pressurisation was noted in only the solid swallows of one patient $(1 / 20[5 \%])$. Jackhammer (hypercontractile) oesophagus patients had at least one elevated DCI with every swallow type. In patients with jackhammer and oesophageal spasm, pan-oesophageal pressurisation was noted in 10/40 (25\%) patients and elevated intrabolus pressure $>20 \mathrm{mmHg}$ in $21 / 40$ (53\%) of patients only in adjunctive tests and not in SWS. In patients with oesophageal spasm and type III achalasia, adjunctive swallows had shorter distal latencies than SWS, however, the differences were not statistically significant.

\subsection{Development of Diagnostic Thresholds}

Evaluation of diagnostic thresholds and ROC analysis for IRP in semi-solid and solid swallow are presented in Figure 1. Semi-solid and solid IRP analysis demonstrated "excellent" accuracy of for "all forms of" EGJ dysfunction (achalasia 
Table 3. Adjunctive tests in major oesophageal motility disorders $(n=120)$.

\begin{tabular}{|c|c|c|c|c|c|c|c|}
\hline \multirow{2}{*}{$\begin{array}{l}\text { Single water } \\
\text { Single water }\end{array}$} & \multicolumn{7}{|c|}{ Median $\left(5^{\text {th }}\right.$ and $95^{\text {th }}$ percentile $)$} \\
\hline & Swallow type & $\begin{array}{c}\text { Integrated } \\
\text { relaxation pressure } \\
(\mathrm{mmHg})\end{array}$ & $\begin{array}{l}\text { Distal contractile } \\
\text { integral } \\
\left(\mathrm{mmHg} \cdot \mathrm{cm}^{-1} \cdot \mathrm{s}^{-1}\right)\end{array}$ & Distal latency (s) & $\begin{array}{l}\text { Upper oesophageal } \\
\text { sphincter relaxation } \\
\text { pressure }(\mathrm{mmHg})\end{array}$ & $\begin{array}{l}\text { Attempts } \\
\text { (median) }\end{array}$ & $\begin{array}{c}\text { All swallows } \\
\text { failed } \\
\text { (patient/20[\%]) }\end{array}$ \\
\hline Semi-solid & Single water & $18.3(13.8-25.1)$ & - & - & $4.9(0.7-10.8)$ & - & $20(100)$ \\
\hline \multirow[t]{2}{*}{ Solid } & Semi-solid & $19.1(11.4-29.7)$ & - & - & $3.4(-5.8-16.4)$ & - & $20(100)$ \\
\hline & Solid & $19.6(12.7-37.2)$ & - & - & $3.8(-2.5-14.9)$ & - & $20(100)$ \\
\hline $\begin{array}{c}\text { Type II } \\
\text { achalasia }\end{array}$ & Single water & $26.1(17.6-36.0)$ & - & - & $9.3(1.8-25.3)$ & - & $20(100)$ \\
\hline \multirow[t]{2}{*}{$\mathrm{n}=20$} & Semi-solid & $30.9(18.8-45.8)$ & - & - & $9.3(-1.1-22.0)$ & - & $20(100)$ \\
\hline & Solid & $31.8(17.1-45.3)^{\star * *}$ & - & - & $9.3(-3.8-19.7)$ & - & $20(100)$ \\
\hline $\begin{array}{c}\text { Type III } \\
\text { achalasia }\end{array}$ & Single water & $23.2(16.2-38.5)$ & $5556(3805-10356)$ & $4.7(3.2-8.4)$ & $4.8(-0.7-15.4)$ & - & $0(0)$ \\
\hline \multirow[t]{2}{*}{$\mathrm{n}=20$} & Semi-solid & $25.8(14.0-48.9)$ & $4682(1148.5-30955)$ & $4.4(2.3-8.1)$ & $4.1(-5.8-17.9)$ & 2.3 & $0(0)$ \\
\hline & Solid & $26.8(15.3-60.3)$ & $4912(1511.6-24140)$ & $4.1(2.3-8.3)$ & $3.7(-6.4-10.9)$ & 2.4 & $0(0)$ \\
\hline $\begin{array}{c}\text { EGJ } \\
\text { obstruction }\end{array}$ & $\begin{array}{l}\text { Single } \\
\text { water }\end{array}$ & $18.9(12.5-29.3)$ & $1827(603-4291)$ & $6.0(4.9-8.8)$ & $3.2(-5.4-7.9)$ & - & $0(0)$ \\
\hline \multirow[t]{2}{*}{$\mathrm{n}=20$} & Semi-solid & $22.8(14.9-37.8)^{\star}$ & $2438(403-4542)$ & $5.9(4.3-9.6)$ & $0.9(-8.8-8.9)^{* *}$ & 1.6 & $2(10)$ \\
\hline & Solid & $24.3(13.7-43.1)^{\star *}$ & $1872(402-6453)$ & $6.0(3.3-7.6)$ & $-0.5(-15.2-6.5)^{\star * \star}$ & 1.4 & $1(5)$ \\
\hline Jackhammer & $\begin{array}{l}\text { Single } \\
\text { water }\end{array}$ & $10.4(1.5-14.2)$ & $5505(4110-10665)$ & $6.1(3.2-9.0)$ & $2.4(-8.2-13.1)$ & - & $0(0)$ \\
\hline \multirow[t]{2}{*}{$\mathrm{n}=20$} & Semi-solid & $14.9(4.1-31.8)^{*}$ & $4075(916-16723)$ & $5.8(2.5-9.7)$ & $0.4(-19.1-10.7)^{\star *}$ & 2.5 & $0(0)$ \\
\hline & Solid & $15.0(0.7-30.3)^{\star *}$ & $4622(1092-17355)$ & $5.0(3.7-8.2)$ & $0.6(-12.9-10.8)^{\star \star}$ & 2.3 & $1(5)$ \\
\hline $\begin{array}{l}\text { Oesophageal } \\
\text { spasm }\end{array}$ & $\begin{array}{l}\text { Single } \\
\text { water }\end{array}$ & $9.8(2.3-11.5)$ & $1987(1013-2899)$ & $5.1(3.1-8.9)$ & $4.0(0.3-9.1)$ & - & $0(0)$ \\
\hline \multirow[t]{2}{*}{$\mathrm{n}=20$} & Semi-solid & $11.3(3.8-14.6)^{*}$ & $2234(608-4602)$ & $4.9(2.7-8.8)$ & $3.8(-4.4-10.5)$ & 1.1 & $1(5)$ \\
\hline & Solid & $14.5(5.1-22.4)^{*}$ & $2008(402-4429)$ & $4.3(2.1-8.5)$ & $3.7(-5.9-10.7)$ & 1.6 & $0(0)$ \\
\hline
\end{tabular}

EGJ, oesophagogastric junction; $\mathrm{p}$-value $<0.05^{*}<0.01^{* *}<0.001^{* * *}$ compared to respective 5 -mL SWS value.

and EGJ outflow obstruction) during semi-solid and solid swallows (both AUC > 0.95; P < 0.001). Optimal IRP diagnostic threshold were $15.5 \mathrm{mmHg}$ for both semi-solid and solid swallows. Existing thresholds for hypercontractility and premature contraction are used for semi-solid and solid swallows as no significant difference between the DCI and DL of adjunctive tests and SWS were observed in neither control nor major motility disorder categories, in keeping with the findings with standard test meals by Sweis et al., 2014 [5]. The number of abnormal swallows required for CCv3.0 diagnosis (at least two hypercontractile swallows or $>20 \%$ swallows with premature contraction for SWS) was modified to accommodate the fewer number of adjunctive swallows; at least one abnormal swallow $(\geq 50 \%)$ to categorise adjunctive swallows as jackhammer or spasm. 


\begin{tabular}{|c|c|c|c|c|c|c|}
\hline & \multicolumn{2}{|c|}{ EGJ dysfunction IRP } & \multicolumn{2}{|c|}{ Hypercontractility DCI } & \multicolumn{2}{|c|}{ Premature contraction DL } \\
\hline & $\begin{array}{c}\text { Semi- } \\
\text { solid } \\
>15.5\end{array}$ & $\begin{array}{l}\text { Solid } \\
>15.5\end{array}$ & $\begin{array}{l}\geq 50 \% \text { semi-solid } \\
\text { swallows }>8000\end{array}$ & $\begin{array}{c}\geq 50 \% \text { Solid } \\
\text { swallows } \\
>8000\end{array}$ & $\begin{array}{c}\geq 50 \% \\
\text { semi-solid } \\
\text { swallows } \\
<4.5\end{array}$ & $\begin{array}{c}\geq 50 \% \text { solid } \\
\text { swallows } \\
<4.5\end{array}$ \\
\hline Sensitivity & 0.92 & 0.92 & 0.35 & 0.2 & 0.68 & 0.78 \\
\hline Specificity & 0.93 & 0.93 & 1.0 & 1.0 & 1.0 & 1.0 \\
\hline PPV & 0.91 & 0.89 & 1.0 & 1.0 & 1.0 & 1.0 \\
\hline NPV & 0.95 & 0.96 & 0.92 & 0.90 & 0.92 & 0.94 \\
\hline $\mathrm{LR}+$ & 13.1 & 13.1 & - & - & - & - \\
\hline LR- & 0.09 & 0.09 & 0.65 & 0.8 & 0.32 & 0.22 \\
\hline NND & 1.18 & 1.18 & 2.86 & 5 & 1.47 & 1.28 \\
\hline
\end{tabular}

(a)

ROC analysis (semi-solid IRP)

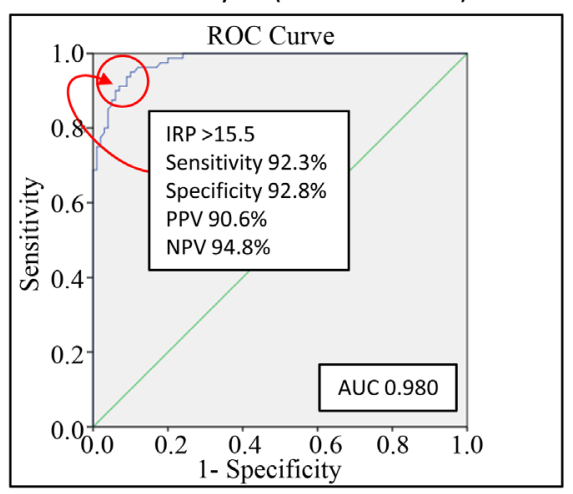

(a)
ROC analysis (solid IRP)

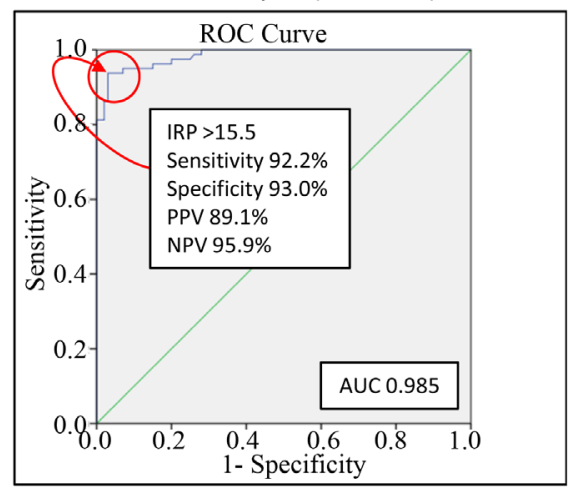

(b)

Figure 1. Optimal diagnostic thresholds were established for semi-solid and solid swallows. Thresholds for hypercontractility and premature contraction utilised single water swallow (SWS) criteria but modified percentage of positive swallows required for diagnosis. (a) Sensitivity and specificity, positive (PPV) and negative predicted values (NPV), positive (LR+) and negative (LR-) likelihood ratios, and numbers needed to diagnosis (NND) for these thresholds are evaluated in patient controls and, minor and major oesophageal motility disorder patients. Receiver operating curve (ROC) analysis based on major motility disorders was used to identify optimal IRP diagnostic thresholds for "all cause" of EGJ dysfunction in (b) ROC for semi-solid swallow IRP and (c) ROC for solid swallow IRP.

\subsection{Application of Diagnostic Thresholds to Patients with Motility Disorders and Oesophagus-Related Symptoms}

Table 4 summaries the patients with a different diagnosis based on adjunctive tests compared to water. Diagnostic thresholds established by ROC analysis was applied to three groups of patients: normal SWS but dysphagia symptoms, patients with minor motility disorders, and patients with major motility disorders. Thirty of the 320 (9.4\%) patients had a different diagnosis based on their adjunctive swallows compared to SWS. The majority of these patients belonged to the group with dysphagia symptoms but normal SWS (12/70, 17\%). Impaired IRP was the most common adjunctive swallow abnormality, present in 22 of the 30 (73\%) cases. Premature contraction, short distal latency, made up the rest of the adjunctive swallow abnormalities (8/30. 27\%). Additional tests or treatment options were recommended by the HRM reporter in all these cases. Follow-up was obtained for 19 of the 30 cases. 
Table 4. Summary of patients with different diagnosis based on adjunctive tests compared to SWS.

\begin{tabular}{|c|c|c|c|c|}
\hline SWS diagnosis & $\begin{array}{l}\text { Abnormal adjunctive } \\
\text { swallows* }\end{array}$ & Defining features of this group & Recommendations & Follow-up \\
\hline Normal (5/100) & $\begin{array}{l}\text { - Impaired IRP } \\
(\mathrm{n}=2) \\
\text { - Short DL }(\mathrm{n}=3)\end{array}$ & - None & $\begin{array}{l}\text { - Gastroscopy of EGJ for the } \\
\text { patients with impaired IRP }\end{array}$ & $\begin{array}{l}\text { - Negative gastroscopy }(\mathrm{n}=3) \\
\text { - No follow-up available } \\
(\mathrm{n}=2)\end{array}$ \\
\hline $\begin{array}{l}\text { Normal with } \\
\text { dysphagia } \\
\text { symptoms (12/70) }\end{array}$ & $\begin{array}{l}\text { - Impaired IRP } \\
(\mathrm{n}=6) \\
\text { - Short DL }(\mathrm{n}=2) \\
\text { - Impaired IRP and } \\
\text { short DL }(\mathrm{n}=4)\end{array}$ & $\begin{array}{l}\text { - Ten of } 12(92 \%) \text { patients had at least one } \\
\text { SWS with abnormal IRP or DL but did } \\
\text { not meet CCv3.0 criteria for motility } \\
\text { disorder diagnosis. } \\
\text { - Nine of } 12(75 \%) \text { patient had reported } \\
\text { dysphagia symptoms exclusively or much } \\
\text { worse with semi-solid or solid swallows. } \\
\text { - Three of } 12(25 \%) \text { patients had } \\
\text { non-specific abnormalities during SWS; } \\
\text { oesophagus shortening, } \\
\text { pan-pressurisation, abnormal swallow } \\
\text { morphology }\end{array}$ & $\begin{array}{l}\text { - Gastroscopy of EGJ for the } \\
\text { patients with impaired IRP } \\
(\mathrm{n}=6) \\
\text { - Repeat HRM in } 12 \text { month } \\
\text { or with worsening } \\
\text { symptoms }(\mathrm{n}=2) \\
\text { - Trial of nitrates or calcium } \\
\text { channel blockers for } \\
\text { patients with short DL } \\
\text { (spasm features } \mathrm{n}=4)\end{array}$ & $\begin{array}{l}\text { EGJ thickening noted by } \\
\text { gastroscopy } \\
(\mathrm{n}=2 \text {, Figure } 2) \\
\text { - Eosinophilic esophagitis } \\
\text { diagnosed by gastroscopy } \\
(\mathrm{n}=1) \\
\text { - Trial of nitrates alleviated } \\
\text { some symptoms }(\mathrm{n}=2) \\
\text { - Negative gastroscopy } \\
(\mathrm{n}=2) \\
\text { - No follow-up available } \\
(\mathrm{n}=5)\end{array}$ \\
\hline $\begin{array}{l}\text { Ineffective } \\
\text { motility }(1 / 30)\end{array}$ & $\begin{array}{l}\text { - Impaired IRP } \\
(\mathrm{n}=1)\end{array}$ & - Two SWS with IRP > 15 mmHg & $\begin{array}{l}\text { - Repeat HRM in } 12 \text { month } \\
\text { or with worsening symp- } \\
\text { toms }\end{array}$ & $\begin{array}{l}\text { Repeat HRM revealed } \\
\text { swallow morphology } \\
\text { characteristic of type II } \\
\text { achalasia in all swallow } \\
\text { types (Figure 3). }\end{array}$ \\
\hline $\begin{array}{l}\text { Jackhammer } \\
(5 / 30)\end{array}$ & $\begin{array}{l}\text { - Impaired IRP } \\
(\mathrm{n}=5)\end{array}$ & $\begin{array}{l}\text { - All patients had at least one SWS with } \\
\text { impaired IRP but did not meet CCv3.0 } \\
\text { criteria for motility disorder diagnosis. } \\
\text { - Three of } 5(60 \%) \text { patients with mean } \\
\text { SWS-IRP on the upper end of normal } \\
\text { (>12 mmHg) } \\
\text { - Elevated mean intrabolus pressure in } \\
\text { SWS }\end{array}$ & $\begin{array}{l}\text { - Diagnosis of evolving type } \\
\text { III achalasia and trial of } \\
\text { calcium channel } \\
\text { blockers/nitrates }(\mathrm{n}=4) \\
\text { - Diagnosis of type III } \\
\text { achalasia and recommended } \\
\text { barium swallow to confirm } \\
(\mathrm{n}=1)\end{array}$ & $\begin{array}{l}\text { Underwent POEM, } \\
\text { significantly reduced } \\
\text { symptoms post-surgery } \\
(\mathrm{n}=1) \\
\text { - Barium swallow/ } \\
\text { gastroscopy provided } \\
\text { additional evidence } \\
\text { suggestive of evolving } \\
\text { achalasia ( } \mathrm{n}=3) \\
\text { - Nitrates in combination } \\
\text { with pneumatic dilation } \\
\text { alleviated some symptoms } \\
(\mathrm{n}=1)\end{array}$ \\
\hline $\begin{array}{l}\text { Oesophageal } \\
\text { spasm (4/30) }\end{array}$ & $\begin{array}{l}\text { - Impaired IRP } \\
(\mathrm{n}=4)\end{array}$ & $\begin{array}{l}\text { Two of } 4(50 \%) \text { patients had at least one } \\
\text { SWS with impaired IRP but did not meet } \\
\text { CCv3.0 criteria for motility disorder } \\
\text { diagnosis. }\end{array}$ & $\begin{array}{l}\text { - Diagnosis of evolving type } \\
\text { III achalasia and trial of } \\
\text { calcium channel } \\
\text { blockers/nitrates }(\mathrm{n}=3) \\
\text { - Diagnosis of type III } \\
\text { achalasia and recommended } \\
\text { barium swallow to confirm } \\
(\mathrm{n}=1)\end{array}$ & $\begin{array}{l}\text { Confirmed evolving } \\
\text { achalasia with barium } \\
\text { swallow/gastroscopy } \\
(\mathrm{n}=1) \\
\text { - Underwent POEM, } \\
\text { significantly reduced } \\
\text { symptoms post-surgery } \\
(\mathrm{n}=1, \text { Figure } 4) \\
\text { Calcium channel blockers } \\
\text { alleviated some symptoms } \\
(\mathrm{n}=1) \\
\text { - No follow-up available } \\
(\mathrm{n}=1)\end{array}$ \\
\hline $\begin{array}{l}\text { EGJ outflow } \\
\text { obstruction }(3 / 30)\end{array}$ & - Short DL $(n=3)$ & $\begin{array}{l}\text { - All patients had at least one SWS with } \\
\text { short DL, rapid contractile front velocity. } \\
\text { - All patients had at least one SWS with } \\
\text { abnormally high focal area of } \\
\text { contractility in the peristaltic body. }\end{array}$ & $\begin{array}{l}\text { Gastroscopy of EGJ for } \\
\text { possible stricture }(\mathrm{n}=3)\end{array}$ & $\begin{array}{l}\text { - Pneumatic dilation, initial } \\
\text { symptom relief but } \\
\text { returned after several } \\
\text { weeks }(\mathrm{n}=1) \\
\text { - } \begin{array}{l}\text { No follow-up available } \\
(\mathrm{n}=2)\end{array}\end{array}$ \\
\hline
\end{tabular}

*Abnormal adjunctive swallows: mean IRP $>15.5 \mathrm{mmHg}$ or $\geq 50 \%$ swallows DCI $>8000 \mathrm{mmHgcm}^{-1} \cdot \mathrm{s}^{-1}$ or $\geq 50 \%$ swallows DL $<4.5 \mathrm{~s}$ in either semi-solid or solid swallows. SWS, single water swallow; IRP, integrated relaxation pressure; DL, distal latency; EGJ, oesophagogastric junction; POEM, peroral endoscopic myotomy. 
Relatively high consistency was observed between SWS and adjunctive tests in the diagnosis of achalasia and EGJ outflow obstruction with 55 semi-solid and 53 solid swallows out of 60 (92\% and 95\% respectively) identifying achalasia and 19/20 (95\%) adjunctive tests identifying EGJ outflow obstruction. Hypercontractility was less evident in adjunctive tests than SWS with only some adjunctive tests displaying DCI $>8,000 \mathrm{mmHg} \cdot \mathrm{cm}^{-1} \cdot \mathrm{s}^{-1}$ patients with jackhammer $(9 / 20$ [45\%]) and type III achalasia (9/20 [45\%]).

\section{Discussion}

The use of water swallows does not always provide enough simulation on oesophageal function to trigger the causes of dysphagia. Past authors have recommended the inclusion of semi-solid and solid swallows to increase sensitivity to symptomatic dysmotility and dysfunction [4] [9] [10] [11] [12] [13]. Although studies have established normal HRM metrics for semi-solid [3] and solid [4] swallows, these studies consisted of relatively small numbers of healthy individuals, 41 and 23 respectively. The pressure records for semi-solid and solid boluses are more complex and exaggerated than water swallows and would require a large number of normal and diseased studies to characterise. We analysed 220 patient controls and major motility disorder cases to establish diagnostic thresholds for semi- solid and solid swallows. The adjunctive test thresholds were able to identify classifiable pathology not detected in patients with relatively normal water swallow or minor motility disorders. Our choice of custard or jelly for semi-solid and marshmallow for solid swallows provide a known and normalised swallow consistency that can be reliably repeated for the evaluation of multiple patients. Previous studies using similar materials, apple sauce and marshmallow, have also found increased frequency of abnormal contractions in subjects with dysphagia compared to water swallows [2].

In our patient controls, an increase in bolus viscosity correlated with an increase in IRP. Past authors analysing similar bolus material have suggested this could be due to increased friction between the bolus and luminal wall [4] [9] Unlike water swallows, we noted that semi-solid and solid boluses often require more than a single swallow to clear but had lower peristaltic amplitudes. This is consistent with studies using other non-liquid bolus swallows [3] [4]. The difference in UES relaxation pressures between adjunctive swallows and SWS are due to two factors; bolus viscosity and volume. Small volumes of viscus boluses lead to a conscious effort to swallow from the participant, generating a higher pharyngeal driving force compared to water, which in turn causes a more relaxed UES. Previous studies report similar increases in UES relaxation with increased bolus viscosity and reduced bolus size, measured by water-perfused manometry [14] and more recently solid-state manometry [15].

A recent study justified the use of "patient controls" as part of the control group because they found no significant difference between the patient controls and healthy asymptomatic volunteers (IRP $20.1 \pm 9.1$ vs $16.3 \pm 8.1 ; \mathrm{P} \geq 0.05$ ) and 
proposed that the inclusion of "patient controls" ensured that reference values were more representative of the patient population [8]. However, unlike the study by Ang et al., we excluded patients with dysphagia symptoms but normal HRM and 24-hour pH studies from our "patient controls" and were analysed these as separate groups.

Semi-solid and solid swallow values were characterised in patients with major oesophageal motility disorders. We noticed semi-solid and solid swallows triggered more profound oesophageal pathophysiology compared with water, such as higher IRP in EGJ dysfunction patients and shorter DL in patients with spasm. These observations are in line with other research that found more frequent oesophageal symptoms and abnormal pathology experienced by patients swallowing non-liquid boluses [3]. Pan-oesophageal pressurisation was more frequently observed in major motility studies during adjunctive tests compared to SWS. The diagnostic significance of pan-oesophageal pressurisation, occurring in the context of EGJ outflow obstruction or achalasia is the consequence of a distinct motor pattern characterised by contraction of both sphincters and the intervening oesophageal longitudinal muscle, but without lumen-obliteration contraction of the circular muscle in the inter-sphincteric span [16]. In contrast, intrabolus pressurisation, recorded from within a compartment trapped between the contractile front to the LES, does not imply necessary downstream obstruction [17] and is of less diagnostic significance. In patients with spasm and type III achalasia, we observed shorter distal latencies and increased peristaltic velocity with semi-solid and solid bolus compared to water. The shorter distal latencies of adjunctive swallows may suggest abnormalities in peristaltic timing and deglutitive inhibition are exaggerated with viscous bolus types. Although clinically interesting, the differences in distal latencies between swallow types were not statistically significant. Literature is mixed on non-liquid peristaltic velocities Basseri et al. [3] found higher velocity with apple sauce in healthy controls while Sweis et al. [4] found lower velocity with bread.

Diagnostic thresholds for semi-solid and solid swallows were established by ROC analysis (Figure 1). The upper of normal IRP we have determined is significantly lower than that of Hollenstein et al., 2017 [13] and Ang et al., 2017 [13] (15.5 mmHg compared to $25 \mathrm{mmHg}$ ). These studies based the $25 \mathrm{mmHg}$ threshold on Sweis et al., 2014 [5]. The differences in thresholds could be attributed to the positions of the participant, upright compared to our values of supine. In addition, this study used a standard size for the single adjunctive swallows, while the others provided a test meal where participants were asked to eat and drink as normal [5] [12] [13]. The test meal approach may provide a more accurate representation of normal eating but results in larger variability between participants. A group of patients with normal SWS but dysphagia symptoms were evaluated based on adjunctive test diagnostic perimeters. The majority of patients that received a different diagnosis based on adjunctive tests all had one or more abnormal SWS but did not have enough to meet diagnostic criteria. The 
trends in SWS are often more exaggerated in the adjunctive tests, which when used as a compliment to SWS, can provide a more definitive diagnosis in cases with borderline SWS abnormalities. In other cases, change in bolus texture can identify food consistencies that are poorly tolerated and induce a different pathological response to water. In Figure 2 a patient experiences dysphagia with solids. Her LES relaxes appropriately with water but becomes progressively more impaired with increasing bolus viscosity. The adjunctive tests are able to identify EGJ outflow obstruction in a patient with relatively normal water swallows.

The adjunctive test diagnostic thresholds were evaluated in patients with minor and major motility disorders. Thirteen studies received a different diagnosis based on adjunctive swallow compared to SWS. A patient diagnosed with ineffective motility based on SWS (Figure 3), shows evidence of impaired LES relaxation and partial-oesophageal pressurisation during adjunctive tests. This pathophysiology is characteristic of evolving type II achalasia. Patient symptoms worsened over time and type II achalasia was confirmed by repeat HRM, one and a half years since the original study. In this case, the increase challenge of viscous or rigid boluses revealed EGJ motor function defects not present in her water swallows and correctly predicted the progression of the disease.

In patients with major motility disorders, adjunctive tests can provide additional information to assist with choosing the best course of treatment. In one of the patients diagnosed with oesophageal spasm, impaired LES relaxation was also suspected but the SWS IRP was just within normal limits (Figure 4). Adjunctive tests further suggested type III achalasia which instigated additional diagnostic tests (barium swallow and gastroscopy) before the patient to undergo peroral endoscopic myotomy (POEM). Additional insight into the mechanism of diseases provided by semi-solid or solid swallows can help expedite diagnosis to enable early clinical intervention.

In our patient group, adjunctive tests are most effective in the diagnosis of

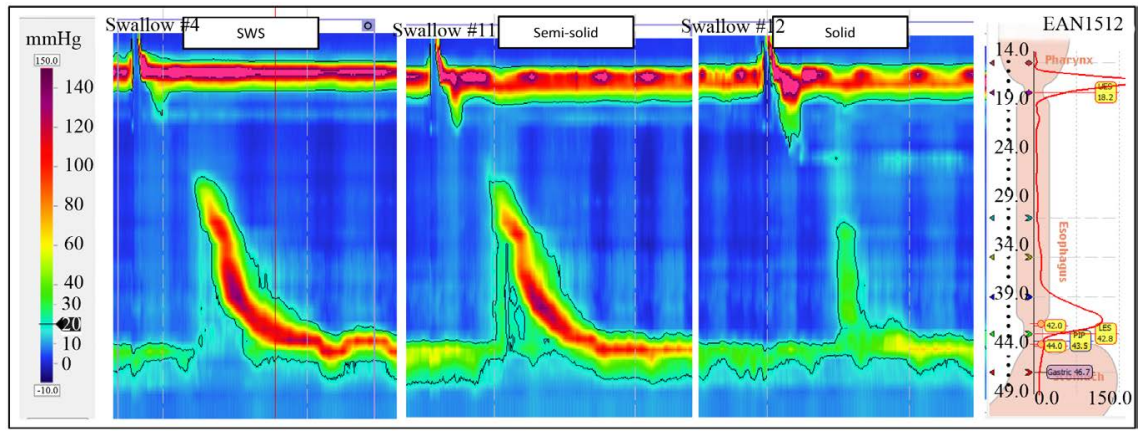

Figure 2. A 54-year-old woman with dysphagia to solids. Manometry at isobaric contour $20 \mathrm{mmHg}$ with single water swallows (SWS) show integrated relaxation pressure (IRP) within normal limit (12.7 mmHg). However, in semi-solid swallow, IRP increased to 16.1 $\mathrm{mmHg}$ and intrabolus pressure $18.9 \mathrm{mmHg}$ was elevated. Solid swallow IRP was higher at $20.2 \mathrm{mmHg}$. These findings reveal impaired oesophagogastric junction (EGJ) relaxation and/or opening, the diagnosis was functional or structural EGJ outflow obstruction with endoscopic examination of EGJ recommended. 


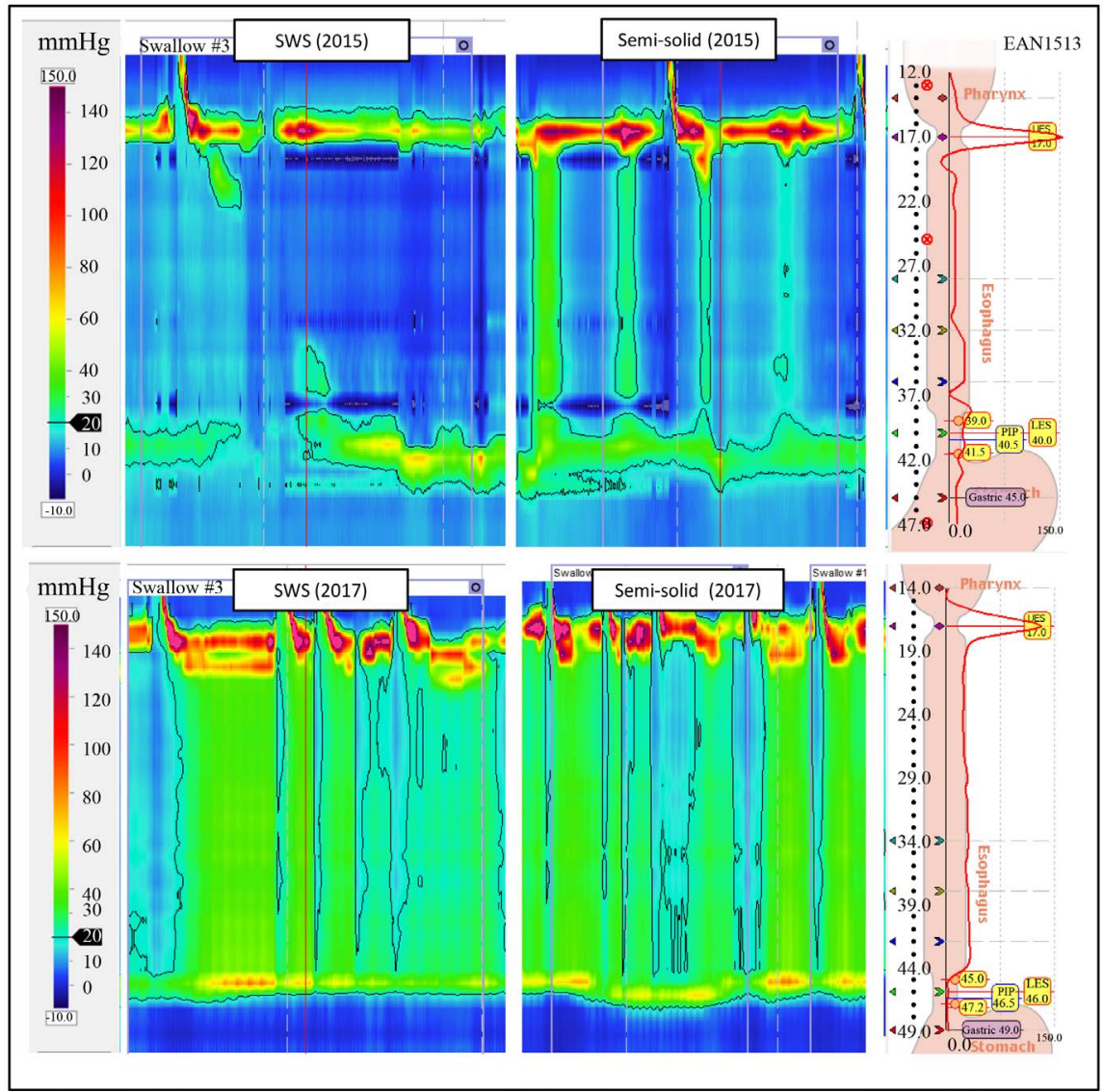

Figure 3. A 61-year-old woman suffered from dysphagia and reflux symptoms. Endoscopy was normal. Barium swallow showed impaired bolus transport. Single water swallows (SWS) revealed ineffective motility ( $>50 \%$ failed swallows and $<450 \mathrm{mmHg}-\mathrm{cm}-\mathrm{s}$ ) but integrated relaxation pressure (IRP) was normal $(11.8 \mathrm{mmHg})$. During semi-solid swallow the IRP was impaired $(21.1 \mathrm{mmHg})$ and oesophageal pressurisation was noted, similarly in solid swallows. Over a period of 1.5 years the patient experienced more frequent and severe symptoms. On repeat manometry, all swallows show impaired IRP and pan-oesophageal pressurisation, pathological of Type II achalasia.

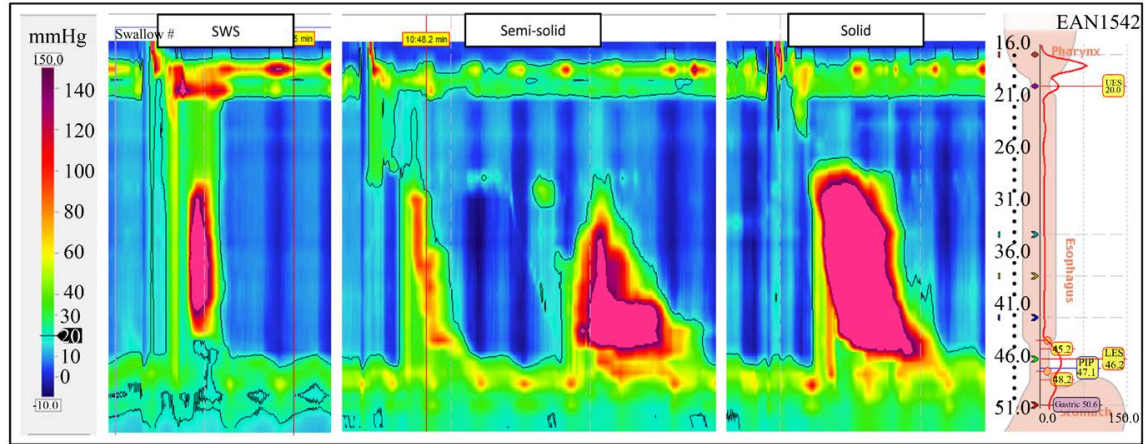

Figure 4. A 53-year-old man experienced chest pains and dysphagia with all liquids and solids. Single water swallows (SWS) showed oesophageal spasm with boarder line normal integrated relaxation pressure (IRP $14.7 \mathrm{mmHg}$ ). Type III achalasia was suspected. Semi-solid and solid swallows triggered larger spasm responses and IRP well over normal limits. Patient was diagnosed Type III achalasia and underwent peroral endoscopic myotomy (POEM). Patient has significantly reduced symptoms 1 year post-operation. 
EGJ dysfunction compared (NND 1.18) to hypercontractility (NND 2.86 - 5) and premature contraction $(1.28-1.47)$. Nine of 40 adjunctive swallows in patients with spasm or jackhammer oesophagus had evidence of EGJ outflow obstruction. In some cases this represents evolving type III achalasia, in other, muscle hyperplasticity with impaired LES compliance [18].

Hypercontractility was not identified in any adjunctive tests apart from jackhammer and type III achalasia. Premature contractility was seen in 7 dysphagia patients and 3 EGJ outflow obstruction patients. This correlates with past findings of increased diagnostic yield for diffused oesophageal spasm and magnified abnormalities seen during standard water swallows with ingestion of food during manometry [10].

Swallows of semi-solid and solid bolus are shown to increase the identification of motility disorders in this study. Patient groups with dysphagia or underlying EGJ dysfunction are mostly likely to benefit from these adjunctive tests. The high specificity and sensitivity achieved with only two semi-solid and solid swallows makes the addition of adjunctive tests relatively time and cost effective in a clinical setting. It would be recommended to incorporate adjunctive swallows with semi-solid and solid bolus types into clinical practise in cases where the patient experiences dysphagia.

A limitation of our study is the absence of a validation set to test our diagnostic thresholds. In addition, the HRM data was collected at a tertiary care centre in which a number of patients were referred for HRM by outside gastroenterologists, we were therefore only able to follow up on approximately half of the patients and assess their progression or response to treatment. It would have been helpful to record and quantify patient perception and symptoms during HRM to correlate with the physiological changes during adjunctive tests. This would determine the value of semi-solid and solid swallows in replicating patient symptoms during manometry. From this study we noted emphasised manometric abnormalities during adjunctive swallow compared to water counter-parts. If this translates to symptoms would be of significant interest. Ang et al., 2017 [12] found an $80 \%$ association between reported oesophageal symptoms and manometric abnormalities during standard test meals. They also describe that symptoms are more likely to occur after the first minute of the meal. This may suggest that we would have detected a weaker symptom association, had this been measured. This study also does not address the issue of a standardised bolus for solid and semi-solid swallows. This means that the normative data set is specific to the food substances/volumes used here, but may not be applicable to other protocols. However, our result using two different semi-solids, custard and jelly, suggests that identical volumes of different semi-solids produce relatively similar HRM metrics. Further research is required to determine the HRM metrics for different foods types. Zhang et al., 2013 highlights the need for a standardised protocol [19]. In keeping with our finding, Hollentstein et al., 2014 [13] found that results from rice standard meal and soft pasty were almost identical. 
This perhaps suggests that the bolus properties do not affect the manometric outcomes.

\section{Conclusion}

In summary, semi-solid and solid swallows increase the identification of classifiable motility disorders when water swallows fail to identify an abnormality in patients presenting with dysphagia. Viscous bolus types provide challenges to the oesophagus akin to ingestion of meals that can increase the yield of pathologic findings compared to water swallows. The additional information can help reclassify a previously unnoticed diagnosis and assist in better disease intervention. With few barriers to implement these alternative swallowing tests, we recommend they be introduced as a useful compliment to the standard SWS in routine clinical studies.

\section{References}

[1] Kahrilas, P.J., Bredenoord, A.J., Fox, M., Gyawali, C.P., Roman, S., Smout, A.J., Pandolfino, J.E., International High Resolution Manometry Working Group (2015) The Chicago Classification of Esophageal Motility Disorders, v3.0. Neurogastroenterology \& Motility, 27, 160-174. https://doi.org/10.1111/nmo.12477

[2] Keren, S., Argaman, E. and Golan, M. (1992) Solid Swallowing versus Water Swallowing: Manometric Study of Dysphagia. Digestive Diseases and Sciences, 37, 603-608. https://doi.org/10.1007/BF01307587

[3] Basseri, B., Pimentel, M., Shaye, O.A., Low, K., Soffer, E.E. and Conklin, J.L. (2011) Apple Sauce Improves Detection of Esophageal Motor Dysfunction during High-Resolution Manometry Evaluation of Dysphagia. Digestive Diseases and Sciences, 56, 1723-1728. https://doi.org/10.1007/s10620-010-1513-x

[4] Sweis, R., Anggiansah, A., Wong, T., Kaufman, E., Obrecht, S. and Fox, M. (2011) Normative Values and Inter-Observer Agreement for Liquid and Solid Bolus Swallows in Upright and Supine Positions as Assessed by Esophageal High-Resolution Manometry. Neurogastroenterology \& Motility, 23, 509-e198. https://doi.org/10.1111/j.1365-2982.2011.01682.x

[5] Sweis, R., Anggiansah, A., Wong, T., Brady, G. and Fox, M. (2014) Assessment of Esophageal Dysfunction and Symptoms during and after a Standardized Test Meal: Development and Clinical Validation of a New Methodology Utilizing High-Resolution Manometry. Neurogastroenterology \& Motility, 26, 215-228. https://doi.org/10.1111/nmo.12252

[6] Richter, J.E. (1997) Ambulatory Esophageal pH Monitoring. The American Journal of Medicine, 103, 130S-134S. https://doi.org/10.1016/S0002-9343(97)00338-0

[7] Pandolfino, J.E., Fox, M.R., Bredenoord, A.J. and Kahrilas, P.J. (2009) High-Resolution Manometry in Clinical Practice: Utilizing Pressure Topography to Classify Oesophageal Motility Abnormalities. Neurogastroenterology \& Motility, 21, 796-806. https://doi.org/10.1111/j.1365-2982.2009.01311.x

[8] Ang, D., Hollenstein, M., Misselwitz, B., Knowles, K., Wright, J., Tucker, E., Sweis, R. and Fox, M. (2017) Rapid Drink Challenge in High-Resolution Manometry: An Adjunctive Test for Detection of Esophageal Motility Disorders. Neurogastroenterology \& Motility, 29, e12902. https://doi.org/10.1111/nmo.12902

[9] Fox, M.R. and Bredenoord, A.J. (2008) Oesophageal High-Resolution Manometry: Moving from Research into Clinical Practice. Gut, 57, 405-423. 
https://doi.org/10.1136/gut.2007.127993

[10] Allen, M.L., Mellow, M.H. and Robinson, M. (1992) Manometry during Food Ingestion Aids in the Diagnosis of Diffuse Esophageal Spasm. The American Journal of Gastroenterology, 87, 568-571.

[11] Bohn, B., Bonaz, B., Gueddah, N., Rolachon, A., Papillon, E., Bost, R. and Fournet, J. (2002) Oesophageal Motor and Sensitivity Abnormalities in Non-Obstructive Dysphagia. European Journal of Gastroenterology \& Hepatology, 14, 271-277. https://doi.org/10.1097/00042737-200203000-00011

[12] Ang, D., Misselwitz, B., Hollenstein, M., Knowles, K., Wright, J., Tucker, E., Sweis, R. and Fox, M. (2017) Diagnostic Yield of High-Resolution Manometry with a Solid Test Meal for Clinically Relevant, Symptomatic Oesophageal Motility Disorders: Serial Diagnostic Study. Lancet Gastroenterology \& Hepatology, 2, 654-661. https://doi.org/10.1016/S2468-1253(17)30148-6

[13] Hollenstein, M., Thwaites, P., Butikofer, S., Heinrich, H., Sauter, M., Ulmer, I., Pohl, D., Ang, D., Eberli, D., Schwizer, W., et al. (2017) Pharyngeal Swallowing and Oesophageal Motility during a Solid Meal Test: A Prospective Study in Healthy Volunteers and Patients with Major Motility Disorders. Lancet Gastroenterology \& Hepatology, 2, 644-653. https://doi.org/10.1016/S2468-1253(17)30151-6

[14] Dantas, R.O., Kern, M.K., Massey, B.T., Dodds, W.J., Kahrilas, P.J., Brasseur, J.G., Cook, I.J. and Lang, I.M. (1990) Effect of Swallowed Bolus Variables on Oral and Pharyngeal Phases of Swallowing. American Journal of Physiology, 258, G675-G681. https://doi.org/10.1152/ajpgi.1990.258.5.G675

[15] Butler, S.G., Stuart, A., Castell, D., Russell, G.B., Koch, K. and Kemp, S. (2009) Effects of Age, Gender, Bolus Condition, Viscosity, and Volume on Pharyngeal and Upper Esophageal Sphincter Pressure and Temporal Measurements during Swallowing. Journal of Speech Language and Hearing Research, 52, 240-253. https://doi.org/10.1044/1092-4388(2008/07-0092)

[16] Hong, S.J., Bhargava, V., Jiang, Y.F., Denboer, D. and Mittal, R.K. (2010) A Unique Esophageal Motor Pattern That Involves Longitudinal Muscles Is Responsible for Emptying in Achalasia Esophagus. Gastroenterology, 139, 102-111. https://doi.org/10.1053/j.gastro.2010.03.058

[17] Bredenoord, A.J., Fox, M., Kahrilas, P.J., Pandolfino, J.E., Schwizer, W. and Smout, A.J., International High Resolution Manometry Working Group (2012) Chicago Classification Criteria of Esophageal Motility Disorders Defined in High Resolution Esophageal Pressure Topography. Neurogastroenterology \& Motility, 24, 57-65. https://doi.org/10.1111/j.1365-2982.2011.01834.x

[18] Dogan, I., Puckett, J.L., Padda, B.S. and Mittal, R.K. (2007) Prevalence of Increased esophageal Muscle Thickness in Patients with Esophageal Symptoms. The American Journal of Gastroenterology, 102, 137-145. https://doi.org/10.1111/j.1572-0241.2006.01003.x

[19] Zhang, X., Xiang, X., Tu, L., Xie, X. and Hou, X. (2013) Esophageal Motility in the Supine and Upright Positions for Liquid and Solid Swallows through High-Resolution Manometry. Journal of Neurogastroenterology and Motility, 19, 467-472. https://doi.org/10.5056/jnm.2013.19.4.467 